\title{
Construction of Highly Functionalized Diazoacetoacetates via Catalytic Mukaiyama-Michael Reactions
}

\author{
Yu Liu, Yu Zhang, Noel Jee, and Michael P Doyle* \\ Department of Chemistry and Biochemistry, University of Maryland, College Park,Maryland \\ 20742
}

\begin{abstract}

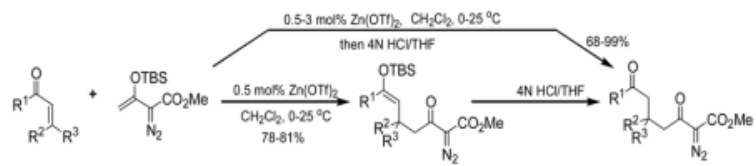

Functionalized diazo acetoacetates are prepared by an efficient Mukaiyama-Michael reaction between methyl 3-(trialkylsilanoxy)-2-diazo-3-butenoate and $\alpha, \beta$-unsaturated enones. Vinyl ether and ketone derivatives are both accessible in good to excellent yield through this methodology. The mild Lewis acid zinc(II) triflate is the optimal catalyst, and it's loading can be as low as 0.1 mol\%. In addition, zinc triflate was also found to be a superior catalyst for the related Mukaiyamaaldol reaction.
\end{abstract}

\begin{abstract}
Metal-catalyzed diazo decomposition of diazoacetoacetate derivatives are among the most well-known reactions for the construction of cyclopropane, cycloalkanone and $\beta$-lactam moieties. ${ }^{1,2}$ The advantages of diazoacetoacetate compounds compared to diazoacetates include their higher thermal and acid stability and greater reaction control during diazo decomposition. ${ }^{1}$ Traditionally these diazo compounds were prepared by multi-step synthesis involving diazo transfer as the final step. ${ }^{3,4}$ Alternative methods were developed which involve the base-mediated condensation of diazo compounds with various electrophiles. 5,6 However these reactions generally require stoichiometric amounts of the reagents under relatively harsh reaction conditions. Although diazo compounds are known to lose their diazo functionality in the presence of Lewis acids, ${ }^{7}$ Calter and Wang independently found various methods for the Lewis acid mediated condensation of diazoacetoacetate compounds and electrophiles. ${ }^{8}$ Despite these advances, efficient syntheses of structurally complex diazo compounds under mild conditions remains a challenging problem.

We recently published an efficient Mukaiyama-aldol reaction between methyl 3(trialkylsilanoxy)-2-diazo-3-butenoate $\mathbf{1}^{9}$ and both aromatic and aliphatic aldehydes $\mathbf{2}$ (Scheme 1) catalyzed by scandium(III) triflate. ${ }^{10}$ These reactions proceeded to form $\mathbf{3}$ in high yield without decomposition of the diazo group. Their success is due, at least in part, to the stability of the vinyldiazonium ion intermediate (4) that is formed by electrophilic addition to $\mathbf{1}$. However, the low Lewis acidity of scandium(III) triflate required relatively long reaction times and limted application to aldehydes with strong electron-withdrawing groups.
\end{abstract}

mdoyle3@umd.edu.

Supporting Information Available: Experimental procedures and spectroscopic data for all new compounds. This material is available free of charge via the Internet at http://pubs.acs.org. 
The Mukaiyama-Michael reaction that is the condensation between enolsilanes and $\alpha, \beta-$ unsaturated carbonyl compounds ${ }^{11}$ is a suitable extension of the Mukaiyama-aldol reaction. Reactions mediated by stoichiometric amounts of strong Lewis acid catalysts have been reported, ${ }^{12}$ and the use of various lanthanides and other Lewis acids as catalysts have been extensively studied. ${ }^{13,14}$ In the only report of a Mukaiyama-Michael reaction to form diazozcetoacetates, ${ }^{8 \mathrm{c}} \mathrm{TiCl}_{4}$ is used in stoichiometric amounts to form the condensation product (eq 1); reactions occurred at $-78^{\circ} \mathrm{C}$, and 1,2 -addition was competitive with 1,4 addition. In view of this, a Mukaiyama-Michael reaction between $\mathbf{1}$ and $\alpha, \beta$-unsaturated carbonyl compounds using catalytic amounts of Lewis acid under milder conditions would be desirable. Herein we report that highly functionalized diazo compounds ( $\mathbf{6}$ and $\mathbf{8}$ ) can be prepared by an efficient Lewis acid-catalyzed Mukaiyama-Michael reaction between $\mathbf{1}$ and enones 5 (Scheme 2) under mild conditions with low catalyst loading of inexpensive zinc triflate. As in previous examples of Mukaiyama-Michael reactions with enolsilanes, silyl group transfer across seven atoms was considered to be a major challenge.

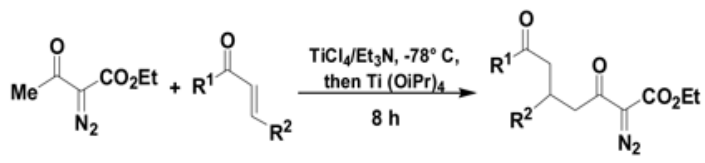

In catalyst screening with cyclohexenone we found that scandium(III) triflate, the previously preferred catalyst for Mukaiyama-aldol reactions of $\mathbf{1},{ }^{10}$ was relatively ineffective for the Michael reaction with the same nucleophile. Thus, reaction of $\mathbf{1}$ with 1.1 equiv of cyclohexenone in the presence of $3.0 \mathrm{~mol} \% \mathrm{Sc}(\mathrm{OTf})_{3}$ gave the Mukaiyama-Michael reaction product (6a) in only $43 \%$ isolated yield after subsequent hydrolysis (entry 1, Table 1),. The low yield was determined to be caused by slow reaction as unreacted cyclohexenone and hydrolyzed silyl enol ether from 1 were also isolated. Lanthanium(III) triflate increased the yield slightly to $50 \%$; however, the reaction was not significantly faster (entry 2 ). The use of boron trifluoride-etherate ${ }^{8 b}$ under the same conditions resulted in decomposition of $\mathbf{6 a}$ (entry 3 ).

In related studies of the $\mathrm{Cu}$ (II) catalyzed Mukaiyama-aldol reactions, silylation of the metal aldolate (silyl transfer) had been proposed to be the rate-limiting step. ${ }^{15 a}$ Furthermore, Ellis and Bosnich concluded that a Lewis acid having a strong alkoxide-Lewis acid bond will inhibit silyl transfer. ${ }^{15 \mathrm{~b}}$ Thus, we focused our attention on the use of less oxophilic Lewis acids. A screening of selected mild Lewis acids (Table 1, entries 4-7) revealed that the inexpensive zinc(II) triflate gave a significantly improved yield (79\%) of MukaiyamaMichael product 6a in the reaction between $\mathbf{1}$ and 1.1 equivalent of cyclohexenone (entry 7). The yield of $6 \mathbf{a}$ could be further improved to $96 \%$ with the use of 1.5 equiv $\mathbf{1}$ (entry 8). ${ }^{16,17}$ Other Lewis acids were found to be much less effective than $\mathrm{Zn}(\mathrm{OTf})_{2}$; with $\mathrm{Cu}(\mathrm{II})$ and $\mathrm{Ag}(\mathrm{I})$ triflate diazo decomposition occurs, resulting in a complex reaction mixture and low yield (entries 4, 5). ${ }^{1}$ Having established optimum conditions with $\mathrm{Zn}(\mathrm{OTf})_{2}$, efforts were undertaken to reduce the required amount of catalyst: a $96 \%$ yield of $\mathbf{6 a}$ was obtained with $0.5 \mathrm{~mol} \%$ catalyst, and with only $0.1 \mathrm{~mol} \%$ of $\mathrm{Zn}(\mathrm{OTf})_{2}$ the yield of $\mathbf{6 a}$ was $94 \%$.

Using $3 \mathrm{~mol} \% \mathrm{Zn}(\mathrm{OTf})_{2}$ and the optimal conditions for production of 6 reactions of 1 with various $\alpha, \beta$-unsaturated ketones were examined (Table 2). Cyclic enones 5a-5d and several acyclic enones $\mathbf{5 h}-\mathbf{5} \mathbf{j}$ all gave excellent yields of the desired product. ${ }^{18} \beta, \beta$-Disubstituted enones such as $\mathbf{5 e}$ and $\mathbf{5 g}$ are sterically hindered and were previously reported to react sluggishly ${ }^{19}$ or give low yields of Mukaiyama-Michael product. ${ }^{14 a}$ However, although we 
found that its reaction with $\mathbf{1}$ was notably slower than with $\mathbf{5 a}$, the Michael adduct $\mathbf{6 e}$ was still isolated in good yield with 3 mol\% catalyst after 36 hours. Decreased reaction rate was also observed with $\mathbf{5 g}$, but a good yield of $\mathbf{6 g}$ was obtained by increasing the concentration of reactants in the reaction solution. The reaction of methyl vinyl ketone $\mathbf{5} \mathbf{f}$ was facile; however, oligomerization was found to be the major side-reaction. The yield of $\mathbf{5 f}$ could be improved to $74 \%$ by using 2 equivalents of $\mathbf{1}$. Several of these reactions were performed in the presence of only $0.5 \mathrm{~mol} \%$ zinc triflate catalyst and afforded comparable product yield (entries 1, 6, 7). In all cases, only 1,4-addition products were observed and isolated from the reaction mixture.

In performing these reactions we anticipated that silyl enol ether $\mathbf{8}$ would be the major product prior to hydrolysis, and indeed it was. However, the product mixture after $16 \mathrm{~h}$ in a reaction apparatus that was open to the atmosphere contained variable amounts of $\mathbf{6}$ and $\mathbf{8}$ that were marginally reproducible. However, when the reaction apparatus was closed to the atmosphere, only $\mathbf{8}$ was obtained. Zinc triflate is sufficiently hygroscopic to draw water into the reaction solution and cause the hydrolysis of $\mathbf{8}$. Reducing the amount of catalyst and performing the reaction in a closed apparatus resulted in good yields of $\mathbf{8}$, representative examples for which are given in Table 3.

Recognizing the effectiveness of zinc triflate for the Mukaiyama-Michael reaction, we returned to the Mukaiyama-aldol reaction to examine its effectiveness for that transformation (Table 4). The isolated yields of both $\mathbf{3 a}$ and $\mathbf{3 b}$ were slightly higher with zinc triflate than with scandium triflate, and $\mathrm{Zn}(\mathrm{OTf})_{2}$ loading could be as low as $0.1 \mathrm{~mol} \%$. Cinnamaldehyde $\mathbf{2 b}$ undergoes exclusive 1,2-addition with $\mathbf{1}$ in the presence of zinc(II) triflate; no 1,4-addition product was observed (entry 2). Furthermore, zinc(II) triflate was found to catalyze the reactions of 4-nitrobenzaldehyde $\mathbf{2 c}$ and 2-nitrobenzaldehyde $\mathbf{2 d}$, which had previously been found to be unreactive using scandium triflate (entries 3,4 ).

In conclusion, an efficient Mukaiyama-Michael methodology involving reactions between a diazo-containing silyl enol ether and various $\alpha, \beta$-unsaturated ketones has been developed using inexpensive, commercially available, zinc triflate. Reaction conditions are mild, product yields are high under low catalyst loading, and the catalyst is also effective in corresponding Mukiayama-aldol reactions. This methodology can be used for the efficient construction of highly substituted diazo-containing compounds and allow late-stage installation and manipulation of the diazo functionality.

\section{Supplementary Material}

Refer to Web version on PubMed Central for supplementary material.

\section{Acknowledgments}

We gratefully acknowledge the financial support provided by the National Institutes of Health (GM46503) and the National Science Foundation.

\section{References}

1. (a) Doyle, MP.; McKervey, MA.; Ye, T. Modern Catalytic Methods for Organic Synthesis with Diazo Compounds: From Cyclopropanes to Ylides. John Wiley \& Sons; New York: 1998. (b) Doyle, MP. Comprehensive Organometallic Chemistry II. Hegedus, LS., editor. Vol. 12 Chapter 5.2. Pergammon Press; New York: 1995.

2. Recent reviews: (a) Merlic CA, Zechman AL. Synthesis. 2003:1137-1156.(b) Davies HML, Antoulinakis EG. Org React. 2001; 57:1-326.(c) Hodgson DM, Pierard FYTM, Stupple PA. Chem Soc Rev. 2001; 30:50-61.(d)Doyle MP. Ojima I. In Catalytic Asymmetric Synthesis (2). John 
Wiley \& SonsNew York2000(e) Doyle MP, Forbes DC. Chem Rev. 1998; 98:911-935. [PubMed: 11848918] (f) Khlebnikov AF, Novikov MS, Kostikov RR. Adv Heterocycl Chem. 1996; 65:93233.(g) Padwa A, Austin DJ. Angew Chem, Int Ed Engl. 1994; 33:1797-1815.

3. Review: Regitz M, Maas G. Diazo Compounds; Properties and Synthesis. Academic PressOrlando, FL1986

4. (a) Padwa A, Austin DJ, Price AT, Semones MA, Doyle MP, Protopopova MN, Winchester WR, Tran A. J Am Chem Soc. 1993; 115:8669-8680.(b) Doyle MP, Westrum LJ, Wolthuis WNE, See MM, Boone WP, Bagheri V, Pearson MM. J Am Chem Soc. 1993; 115:958-964.(c) Clemens RJ, Hyatt JA. J Org Chem. 1985; 50:2431-2435.

5. Review: Zhao Y, Wang J. Synlett. 2005:2886-2892.

6. (a) Wenkert E, McPherson CA. J Am Chem Soc. 1972; 94:8084-8090.(b) Moody CJ, Morfitt CN. Synthesis. 1998:1039-1042.(c) Kanemasa S, Araki T, Kanai T, Wada E. Tetrahedron Lett. 1999; 40:5059-5062.(d) Jiang N, Wang J. Tetrahedron Lett. 2002; 43:1285-1287.(e) Sa MM, Silveira GP, Bortoluzzi AJ, Padwa A. Tetrahedron. 2003; 59:5441-5447.

7. Holmquist CR, Roskamp EJ. J Org Chem. 1989; 54:3258-3260.

8. (a) Calter MA, Sugathapala PM, Zhu C. Tetrahedron Lett. 1997; 38:3837-3840.(b) Calter MA, Zhu C. J Org Chem. 1999; 64:1415-1419.(c) Deng G, Tian X, Qu Z, Wang J. Angew Chem, Int Ed. 2002; 41:2773-2776.

9. Davies HML, Ahmed G, Churchill MR. J Am Chem Soc. 1996; 118:10774-10780.

10. Doyle MP, Kundu K, Russell AE. Org Lett. 2005; 7:5171-5174. [PubMed: 16268530]

11. Narasaki K, Soai K, Mukaiyama T. Chem Lett. 1974:1223-1224.

12. For representative examples: (a) Heathcock CH, Norman MH, Uehling DE. J Am Chem Soc. 1985; 107:2797-2799.(b) Sato T, Wakahara Y, Otera J, Nozai H, Fukuzumi S. J Am Chem Soc. 1991; 113:4028-4030.(c) Fujita Y, Fukuzumi S, Otera J. Tetrahedron Lett. 1997; 38:2117-2120.(d) Sankararaman S, Sudha R. J Org Chem. 1999; 64:2155-2157. [PubMed: 11674320] (e) Bellassoued M, Mouelhi S, Fromentin P, Gonzalez A. J Organometal Chem. 2005; 690:21722179.

13. For representative examples of Mukaiyama-Michael reactions using catalytic amounts of Lewis acids: (a) Matsuda I, Makino T, Hasegawa Y, Itoh K. Tetrahedron Lett. 2000; 41:1409-1412.(b) Miura K, Nakagawa T, Hosomi A. Synlett. 2003:2068-2070.(c) Jaber N, Assie M, Fiaud J, Collin J. Tetrahedron. 2004; 60:3075-3083.(d) An DL, Peng Z, Orita A, Kurita A, Man-e S, Ohkubo K, Li X, Fukuzumi S, Otera J. Chem Eur J. 2006; 12:1642-1647.(e) Suga H, Takemoto H, Kakehi A. Heterocylces. 2007; 71:361-371.(f) Attanasi OA, Favi G, Filippone P, Lillini S, Mantellini F, Spinelli D, Stenta M. Adv Syn \& Catal. 2007; 349:907-915.

14. For representative examples of asymmetric Mukaiyama-Michael reactions using Lewis acid catalysts: (a) Evans DA, Rovis T, Kozlowski M, Dowey CW, Tedrow JS. J Am Chem Soc. 2000; 122:9134-9142.(b) Evans DA, Scheidt KA, Johnston JN, Willis MC. J Am Chem Soc. 2001; 123:4480-4491. [PubMed: 11457234] (c) Desimoni G, Faita G, Filippone S, Mella M, Zampori M, Zema M. Tetrahedron. 2001; 57:10203-10212.(d) Sibi MP, Chen J. Org Lett. 2002; 4:29332936. [PubMed: 12182592] (e) Wang X, Adachi S, Iwai H, Takatsuki H, Fujita K, Kubo M, Oku A, Harada T. J Org Chem. 2003; 68:10046-10057. [PubMed: 14682699] (f) Suga H, Kitamura T, Kakehi A, Baba T. Chem Commum. 2004:1414-1415.(g) Harada T, Adachi S, Wang X. Org Lett. 2004; 6:4877-4879. [PubMed: 15606089] (j) Ishihara K, Fushimi M. Org Lett. 2006; 8:19211924. [PubMed: 16623585] (h) Takenaka N, Abell JP, Yamamoto H. J Am Chem Soc. 2007; 129:742-743. [PubMed: 17243793]

15. (a) Evans DA, Murry JA, Kozlowski MC. J Am Chem Soc. 1996; 118:5814-5815.(b) Ellis WW, Bosnich B. Chem Commun. 1998; 193-194

16. The use of other common solvents such as chloroform, toluene, THF and ether gave diminished yields of $6 \mathbf{a}$.

17. In contrast to our report of Mukaiyama reaction (ref 10), the OTMS silyl enol ether analog of 1 gave la ower yield of $\mathbf{6}$ than did $\mathbf{1}$. The additional advantage of the OTBS silyl enol ether is its greater stability.

18. Other common Michael acceptors such as $\alpha, \beta$-unsaturated esters, unsaturated nitriles and unsaturated nitro compounds were found to be unreactive under the standard reaction condition. 
19. DuBay WJ, Grieco PA, Todd LJ. J Org Chem. 1994; 59:6898-6899. 


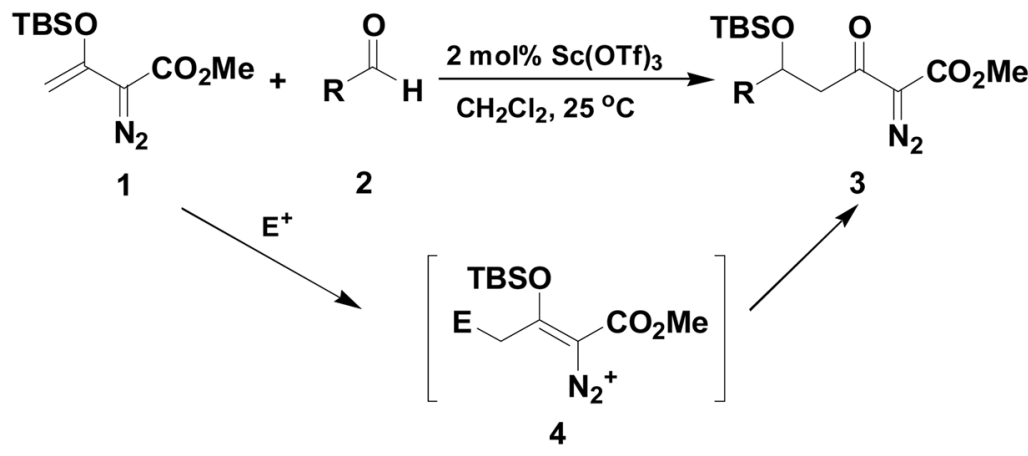

Scheme 1. 


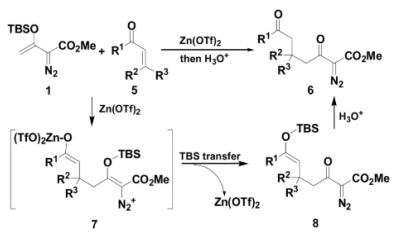

Scheme 2. 


\section{Table 1}

Optimization of the Mukaiyama-Michael Reaction ${ }^{a}$

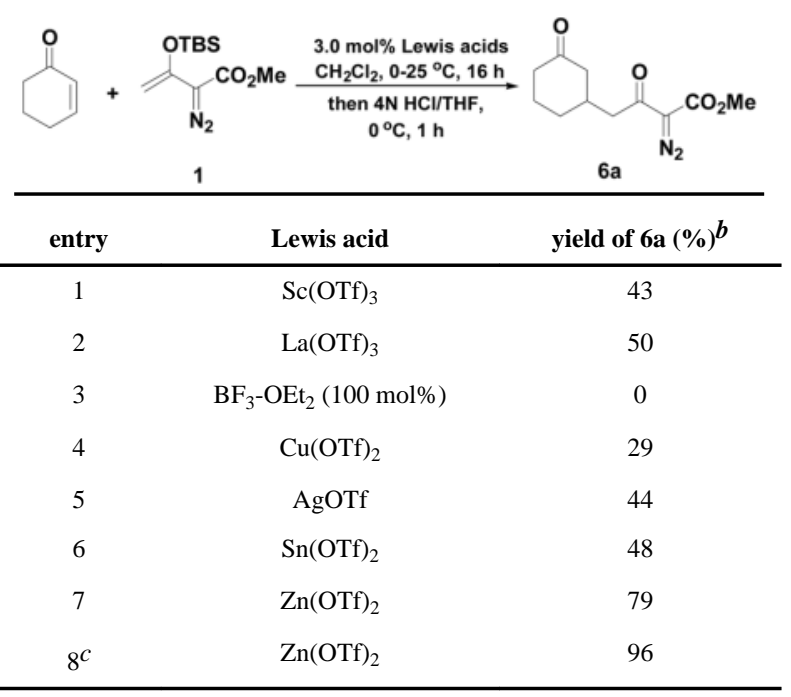

\footnotetext{
${ }^{a}$ Vinyldiazoacetate $\mathbf{1}(0.5 \mathrm{mmol})$ was added to a solution of enone $\mathbf{5 a}(0.55 \mathrm{mmol})$ and metal triflate $(0.015 \mathrm{~mol}) \mathrm{in}_{\mathrm{CH}} \mathrm{Cl}_{2}(2 \mathrm{~mL})$. The solution was stirred at $0^{\circ} \mathrm{C}$ and then allowed to warm up to room temperature. After 16 hours, the crude reaction mixture was concentrated and hydrolyzed with $1: 54 \mathrm{~N} \mathrm{HCl} / \mathrm{THF}$ at $0^{\circ} \mathrm{C}$. See Supporting Information for details.

${ }^{b}$ Yield of isolated 6a following column chromatography.

$c 1.5$ equivalent of 1 was used under the same conditions.
} 
Table 2

Zinc Triflate-Catalyzed Mukaiyama-Michael Reactions of $\mathbf{1}$ with Representative Enones ${ }^{a}$
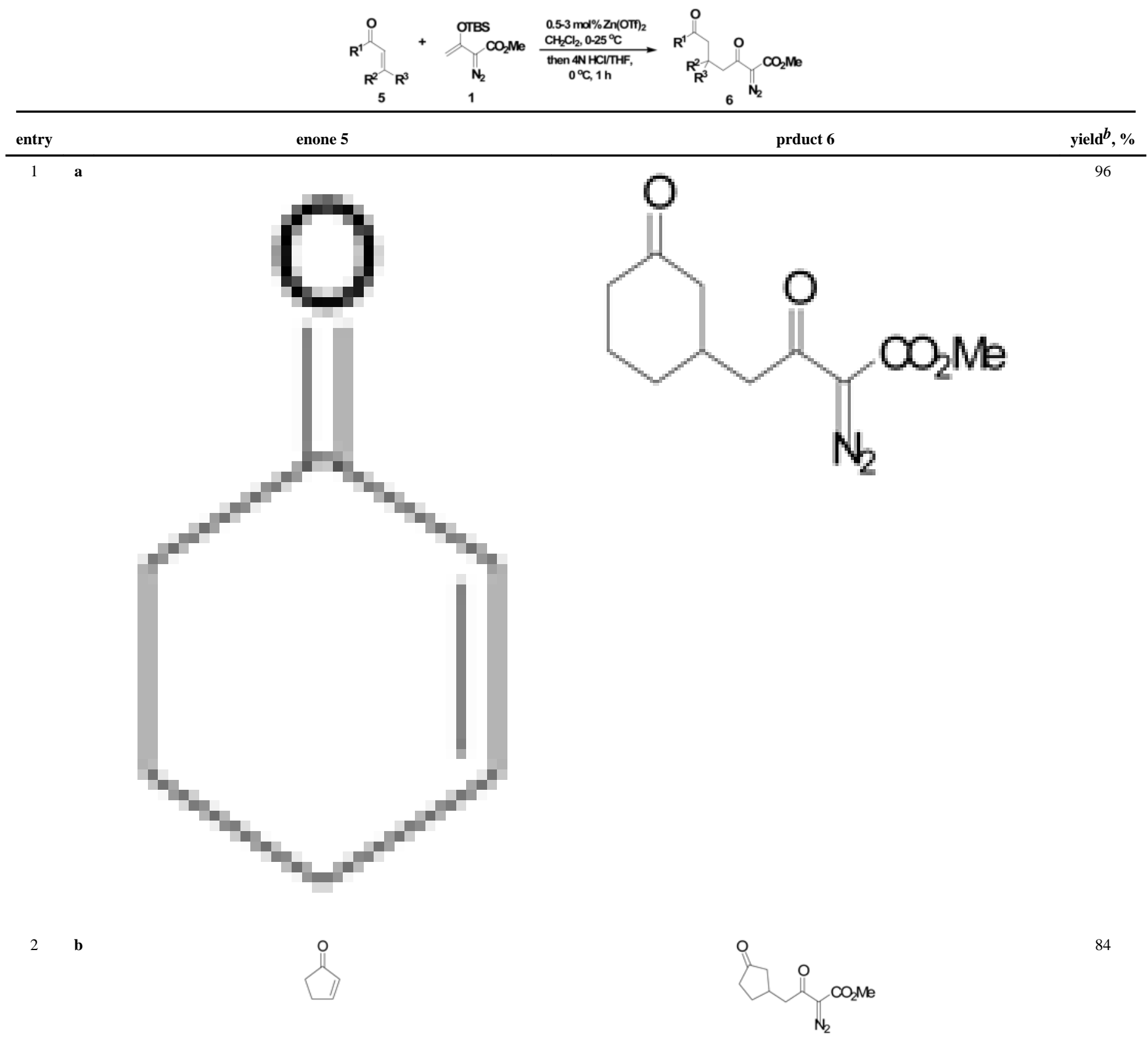

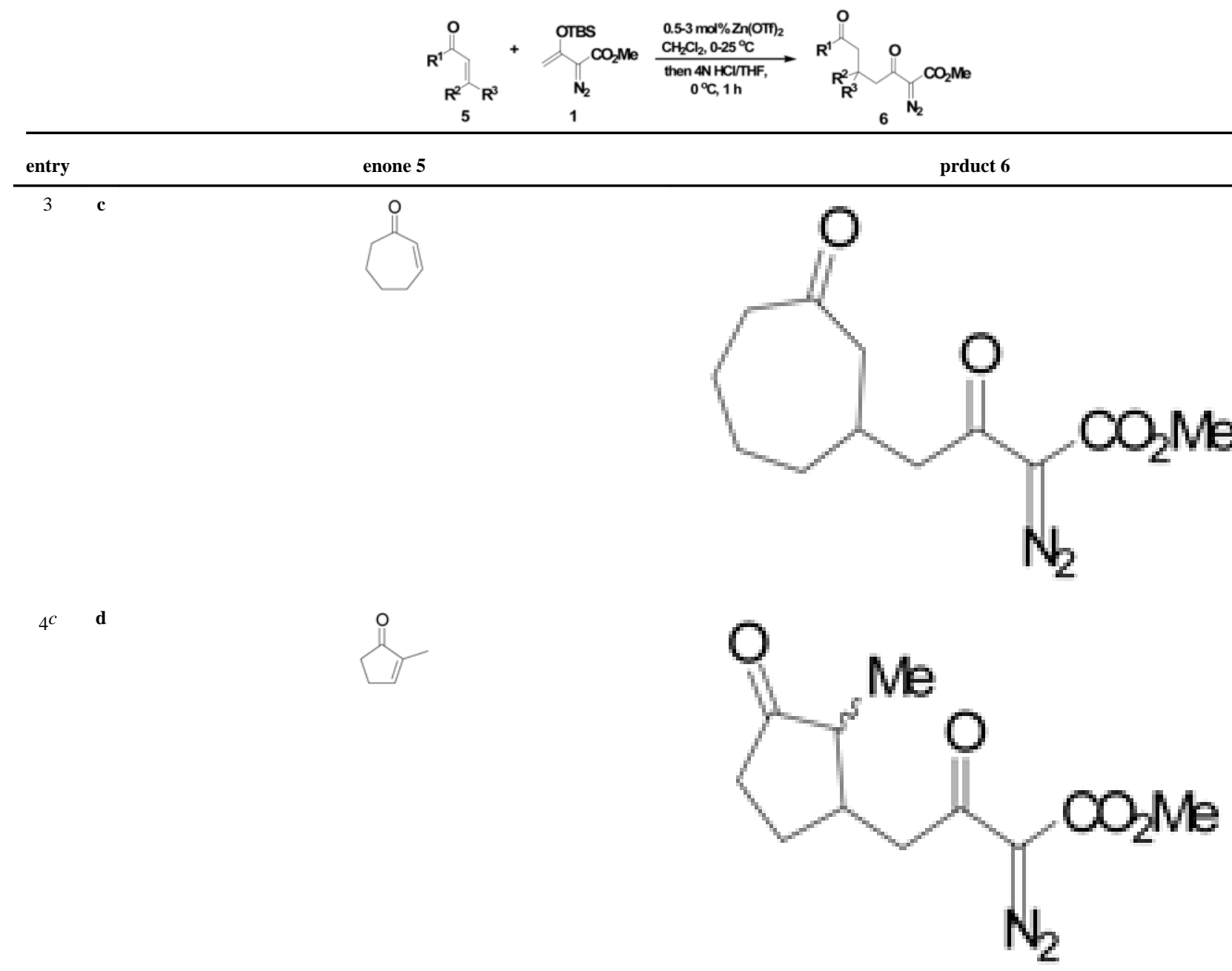

Org Lett. Author manuscript; available in PMC 2011 June 22. 

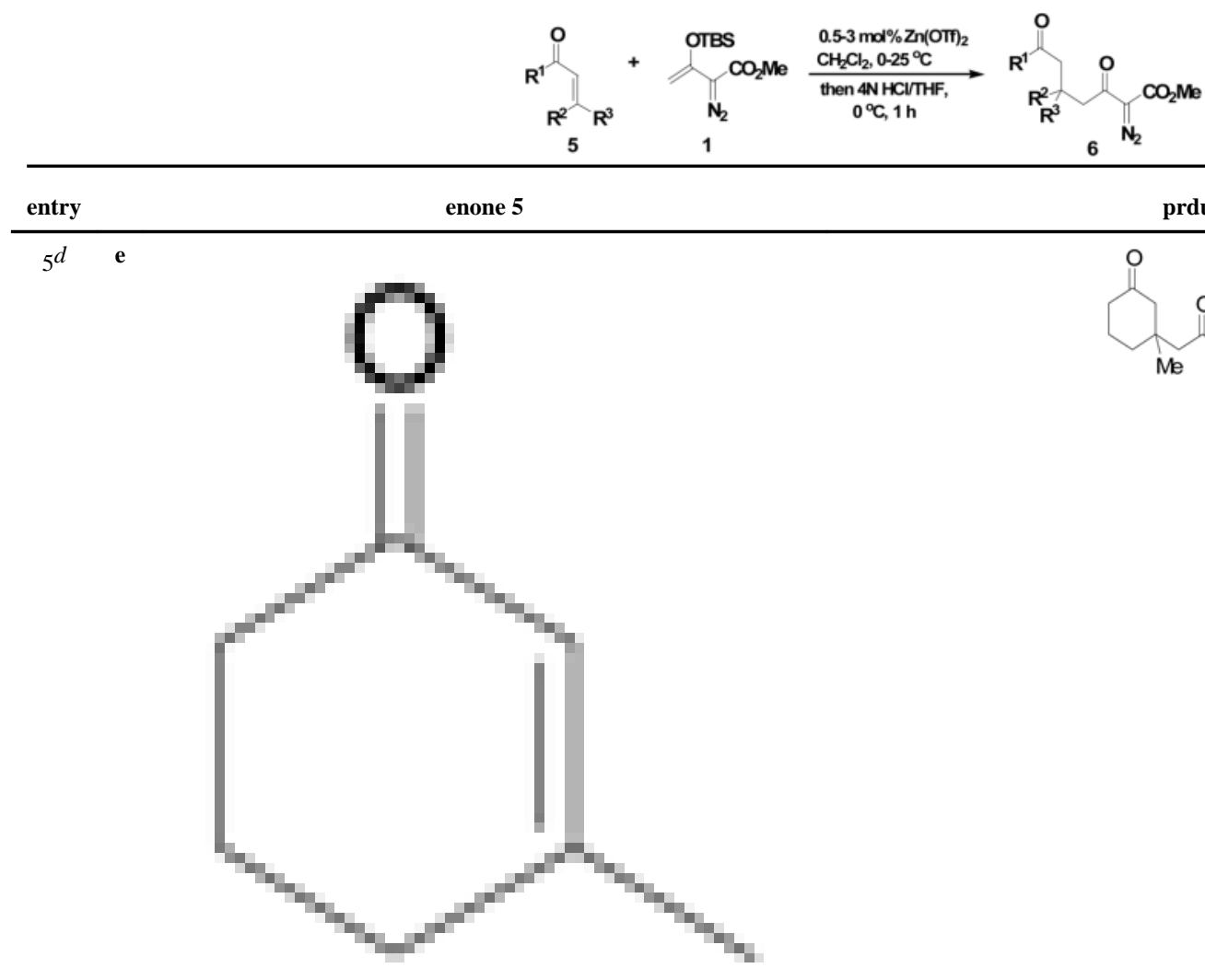

prduct 6

yield $^{b}, \%$

$6^{e} \mathbf{f}$
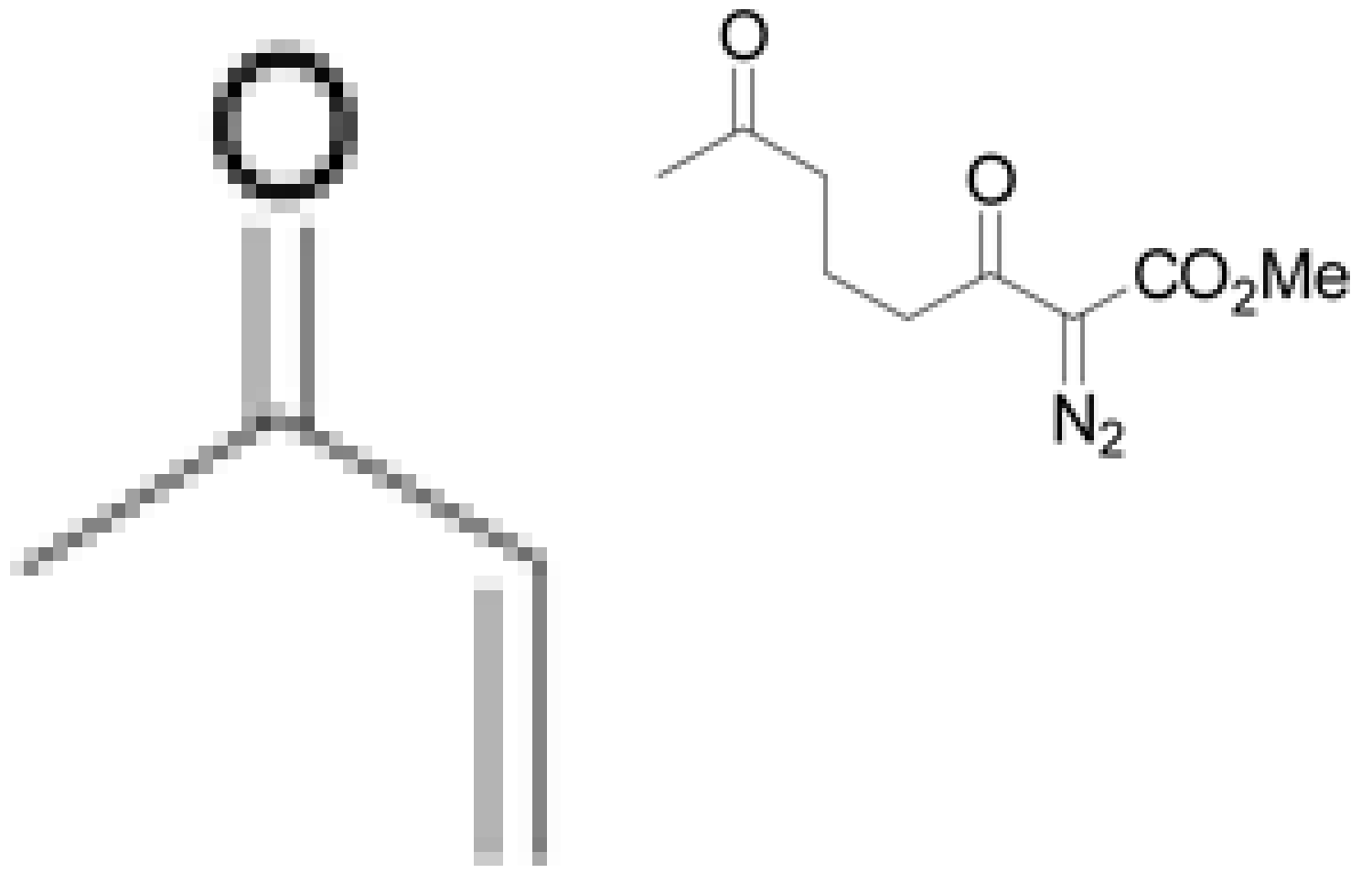

$\mathrm{N}_{2}$ 

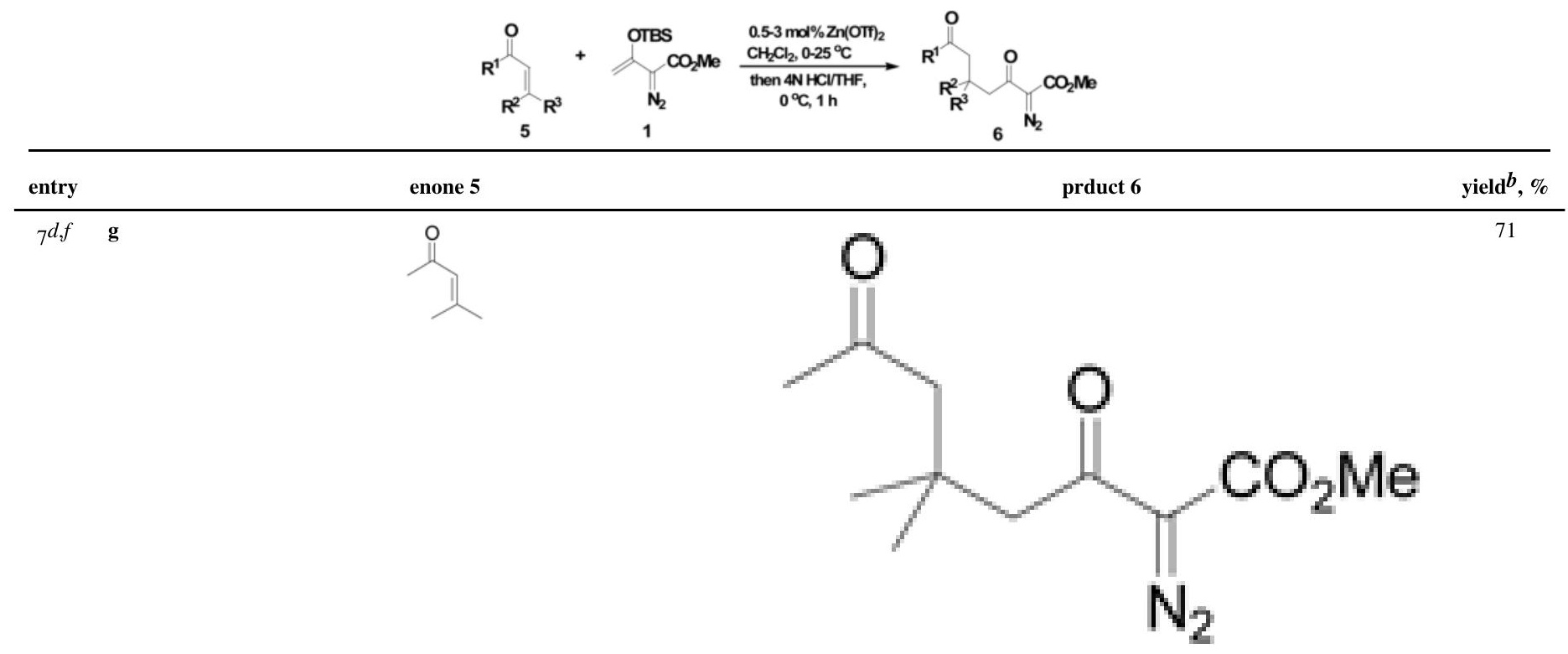

$8 \mathbf{h}$
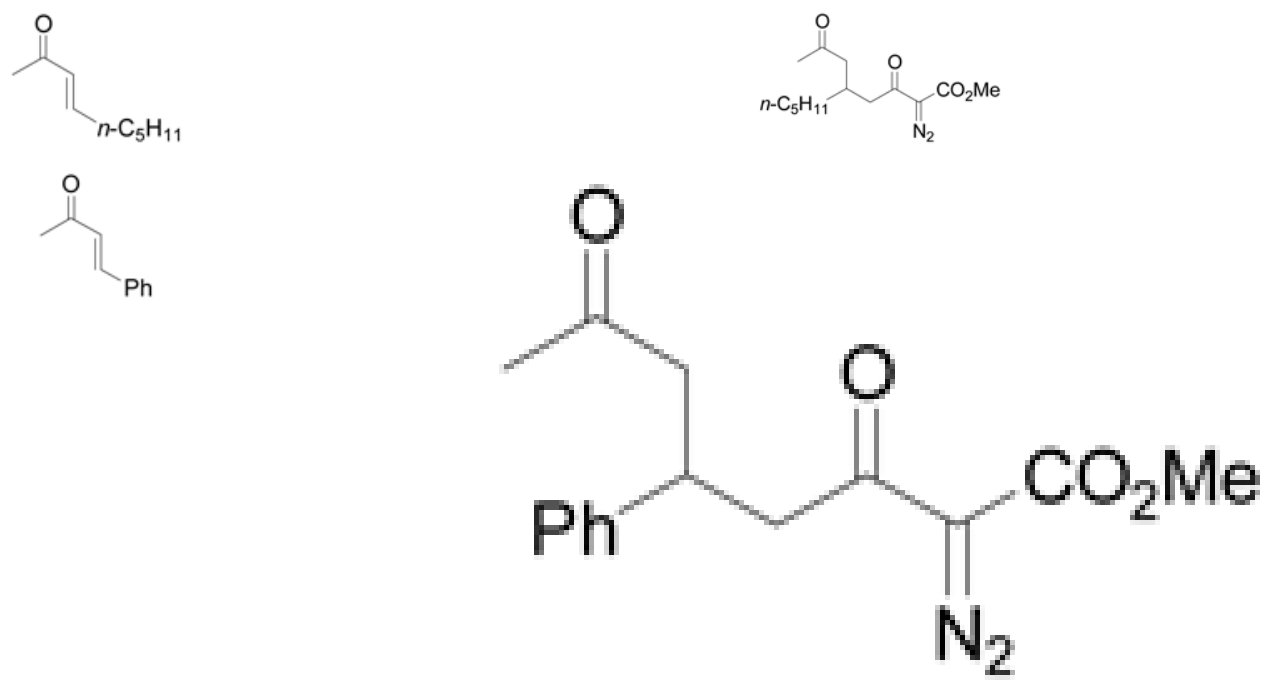

Org Lett. Author manuscript; available in PMC 2011 June 22. 

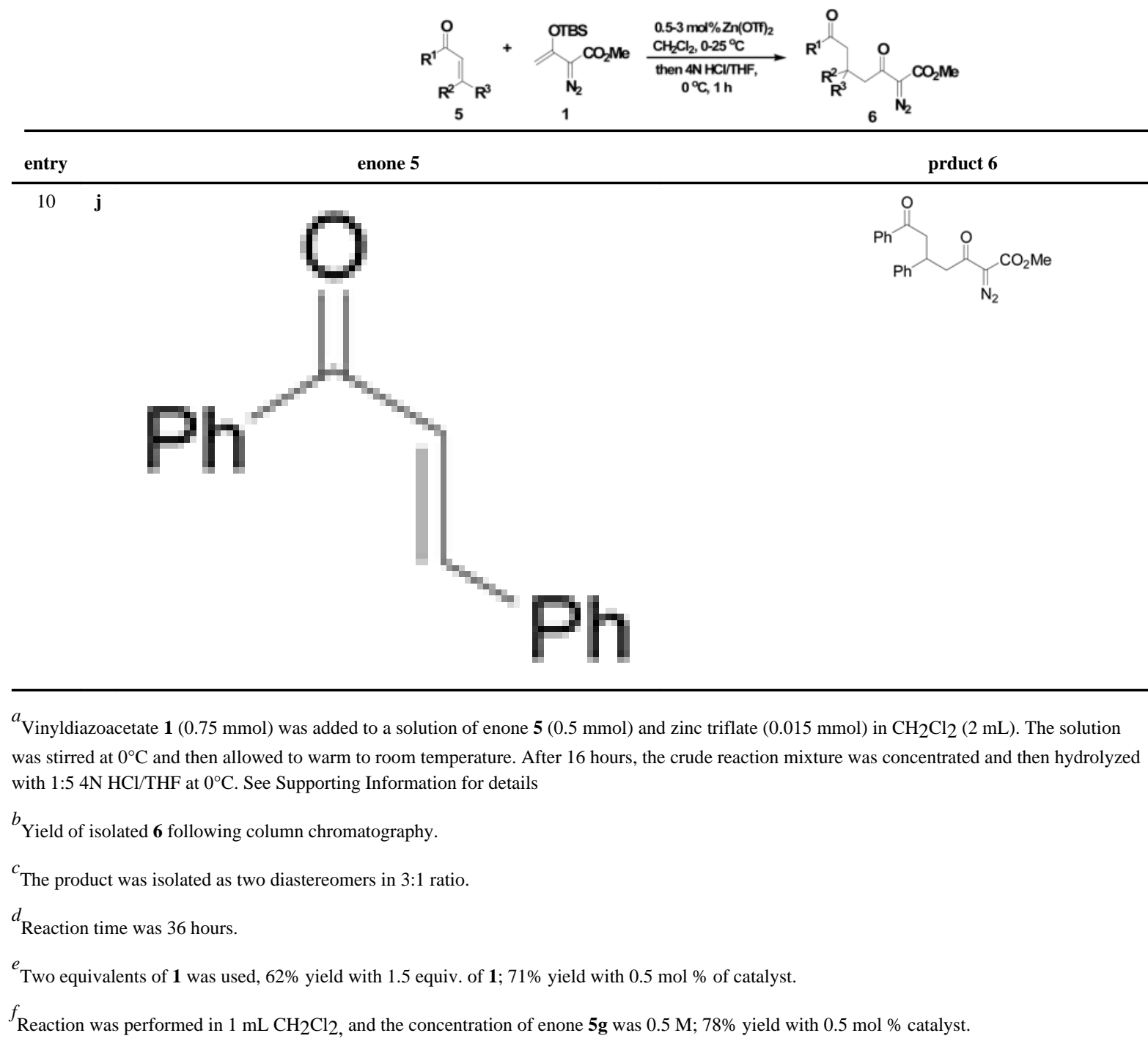

Org Lett. Author manuscript; available in PMC 2011 June 22. 
Table 3

Catalytic Mukaiyama-Michael Reactions of $\mathbf{1}$ with $0.5 \mathrm{~mol} \%$ catalyst loading and lead to product $\mathbf{8}^{a}$

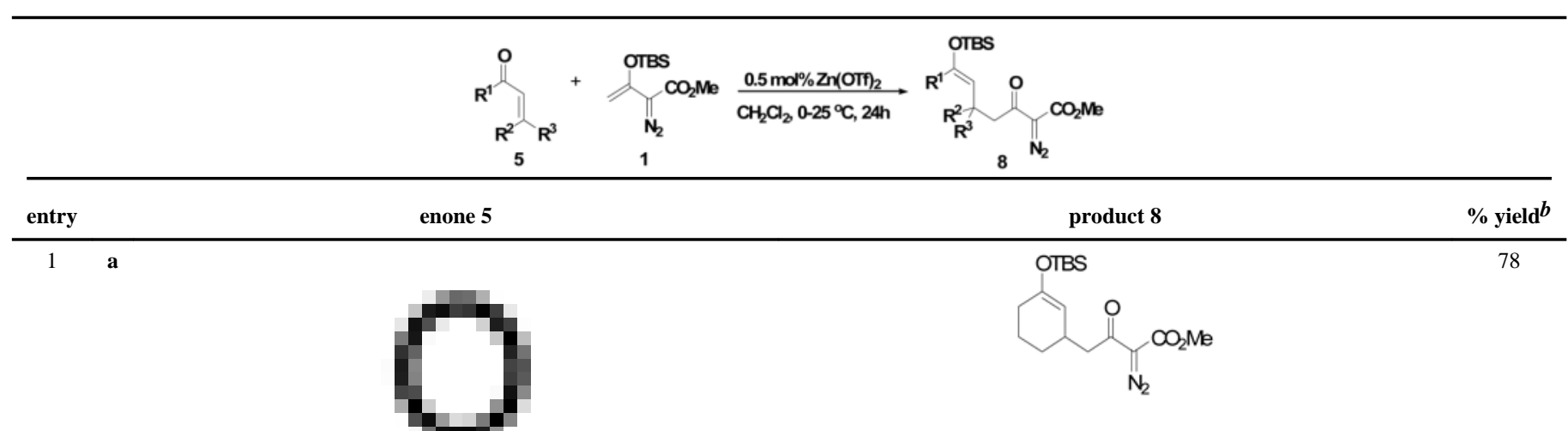

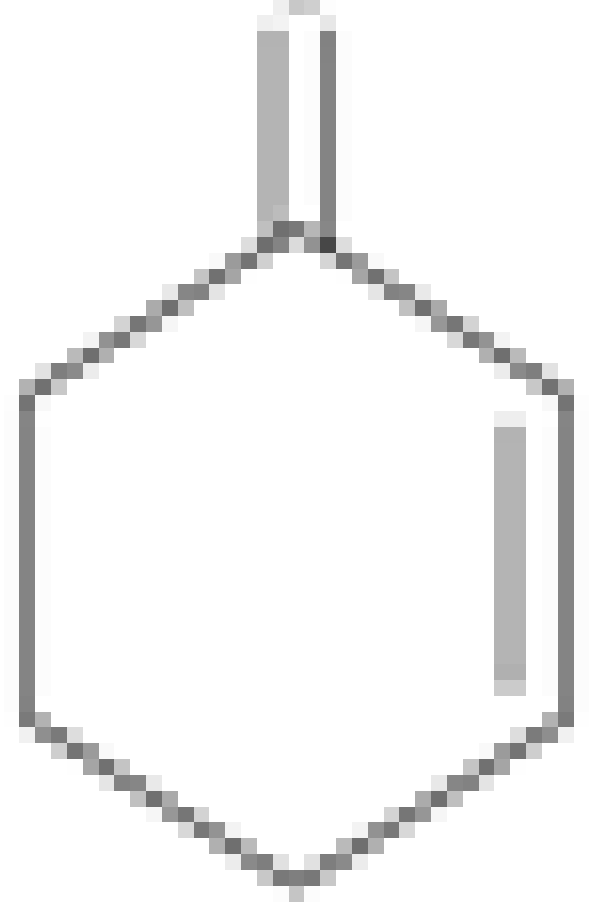




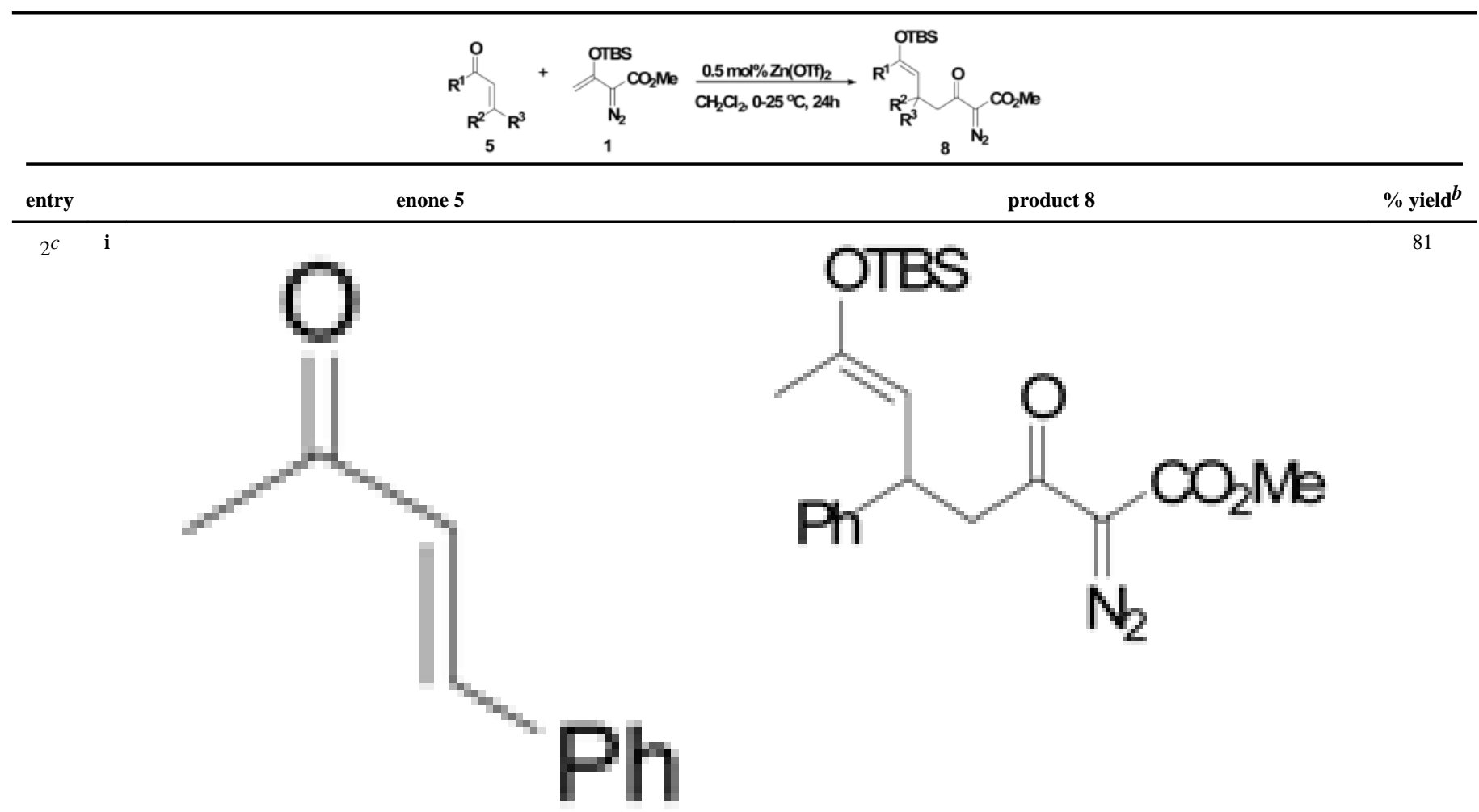

3 j
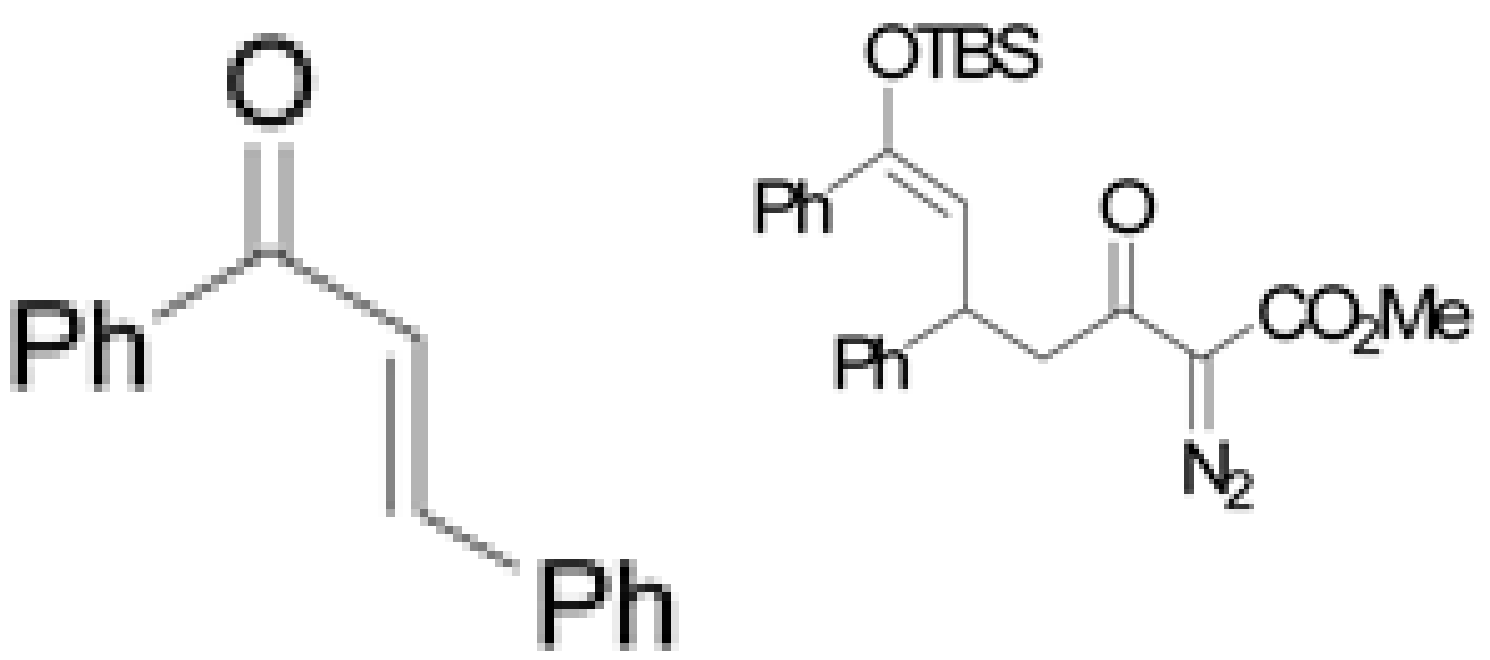

\footnotetext{
${ }^{a}$ Vinyldiazoacetate $\mathbf{1}(0.5 \mathrm{mmol})$ was added to a solution of enone $\mathbf{5}(0.6 \mathrm{mmol})$ and metal triflate $(0.0025 \mathrm{~mol})$ in $\mathrm{CH}_{2} \mathrm{Cl}_{2}(2 \mathrm{~mL})$. The solution was stirred at $0^{\circ} \mathrm{C}$ and then allowed to warm up to room temperature and react for 24 hours.

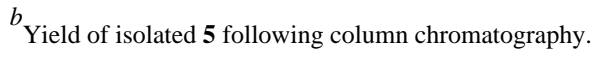

${ }^{c}$ The product was isolated as two diastereomers in 3:1 ratio favoring the $E$-isomer.
} 
Table 4

Zinc(II) Triflate Catalyzed Mukaiyama-aldol Reactions of $\mathbf{1}$ with Representative Aldehydes ${ }^{a}$

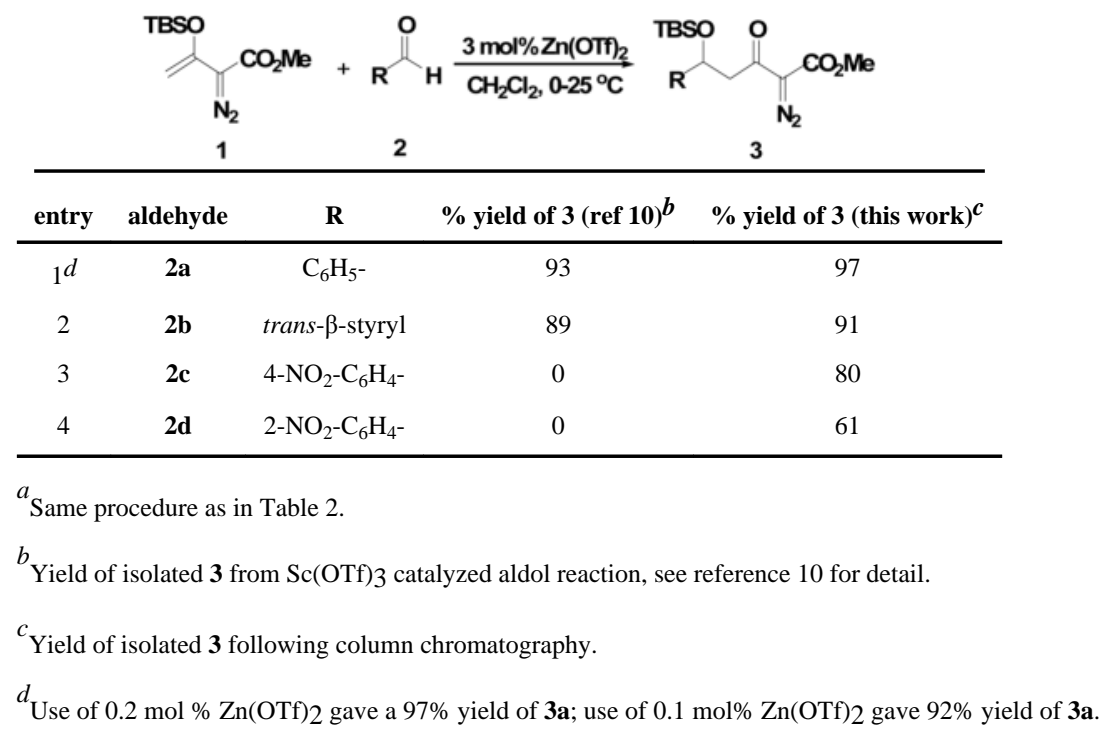

Org Lett. Author manuscript; available in PMC 2011 June 22. 